\title{
Update of WHO air quality guidelines
}

\author{
Michal Krzyzanowski • Aaron Cohen
}

Received: 22 February 2008 / Accepted: 25 April 2008 /Published online: 29 May 2008

(C) Springer Science + Business Media B.V. 2008

\begin{abstract}
Based on a systematic review of literature on adverse health effects of air pollution, the World Health Organization has updated its Air Quality Guidelines in 2005. The current update is intended to be relevant and applicable worldwide and takes into consideration large regional inequalities in exposures to air pollution. It recommends guideline levels for particulate matter, ozone, nitrogen dioxide and sulfur dioxide, as well as the set of interim targets for these pollutants' concentrations, encouraging gradual improvement of air quality and reduction of health impacts of the pollution.
\end{abstract}

Keywords Air Quality Guidelines · Air pollutants ·

Health hazards

\section{Introduction}

In 2005, the World Health Organization (WHO) updated its Air Quality Guidelines (AQG), an international reference on the health consequences of exposure to air pollution and a policy tool for reducing these consequences worldwide. Based on a systematic review of the rapidly growing literature on the adverse health effects of air pollution and drawing on recent estimates of the health impacts of air pollution, the AQG are intended to be relevant and

M. Krzyzanowski $(\bowtie)$

European Centre for Environment and Health, Bonn Office,

World Health Organization,

Bonn, Germany

e-mail: mkr@ecehbonn.euro.who.int

A. Cohen

Health Effects Institute,

Boston, MA, USA applicable worldwide while also being specifically designed to address large regional inequalities in exposures to air pollution and the burden of disease due to such exposure.

The first edition of the WHO AQG for Europe was published in 1987 and was revised in 2000 in a second edition to address the health hazards related to 37 of the most common air pollutants (WHO 2000b). The scientific evidence on the health risks of air pollution and appreciation of the global scale of the air pollution problem have both grown considerably since the second edition of the AQG, and updated guidelines, with true global applicability, were clearly needed. The WHO Regional Office for Europe project "Systematic review of health aspects of air quality in Europe," performed to support the development of the European Commission "Clean Air for Europe" programme in 2002-2004, concluded that the growth of knowledge warranted revision of the air quality guidelines for particulate matter, nitrogen dioxide, and ozone (WHO 2004a). Of critical importance, more studies had been conducted in developing countries in Asia and Latin America, where levels of air pollution are among the highest worldwide, providing stronger evidence of the global nature of the public health challenge posed by air pollution. (HEI 2004; PAHO 2005). The WHO project "Comparative Risk Assessment" (WHO 2004b) pointed to the substantial burden of disease attributable to air pollution, a burden that falls most heavily on developing countries, particularly those in Asia, which are estimated to sustain two thirds of the global burden of disease due to urban outdoor air pollution (Cohen et al. 2004)

Though the AQG are neither standards nor legally binding criteria, they are designed, via expert evaluation of current scientific evidence, to offer guidance for reducing the health impacts of air pollution. The AQG are an important resource for governmental authorities as they develop health-based 
national air quality management strategies, especially in those countries which lack the necessary scientific infrastructure and resources to conduct their own assessments in support of public policy. As such, they are intended to be relevant to the diverse conditions that exist worldwide across WHO's regions and to support a broad range of policy options for air quality management, tailored to suit local conditions, including the following: pollution sources, local economic activities, and technical, social, and political situations, as well as to the resources mobilized for the prevention of risks from environmental hazards.

The AQG are based on expert evaluation of the current state of knowledge about the health effects of exposure to air pollution and the magnitude and geographical distribution of its health impacts. Few countries have sufficient expertise and resources to conduct regular evaluation of the large and continually growing international scientific literature on the health effects of air pollution. For many of those countries, the WHO AQG may be the only feasible scientific support for their policies. In addition, participation in the WHO process of a broad group of top scientists, representing all relevant research disciplines and engaged in research in various regions of the world, assures the highest possible credibility of the AQG. The independence of the WHO experts from any policy restrictions or local considerations, which may affect assessments performed on a national level, further increases the value of this assessment.

This paper presents the process of the recent update of the AQG, discusses some scientific challenges in the guidelines formulation, and evaluates available information on the use of WHO assessments in formulation of national or regional strategies on air quality.

\section{Principles and process of the update}

The update followed the principles established in an earlier WHO guidance document on evaluation of epidemiological evidence for environmental health risk assessment (WHO 2000a). Evidence from many types of relevant studies (epidemiology, clinical studies, toxicological experiments) was reviewed, and the merits of various research approaches in providing information for the AQGs were discussed in one of the introductory chapters. The conclusions were reached by consensus among the experts, and the reasoning leading to the guidelines formulation is recorded in the supporting text. The basis for each AQG is thus transparent.

WHO established a steering group to advise and lead the guideline development process ${ }^{1}$. The Steering Group

\footnotetext{
${ }^{1}$ Steering Group members: RH Anderson (UK), B. Brunekreef (The Netherlands), B. Chen (China), A. Cohen (USA), R. Maynard (UK), I. Romieu (Mexico), KR. Smith (USA), S. Wangwongwatana (Thailand)
}

agreed on the scope and methodology of the update and identified experts to contribute to the review of the scientific literature. The scope of the updated guidelines reflects the Steering Group's judgment concerning both the availability of new evidence on the health effects of specific pollutants and the relative importance of the specific pollutants with regard to current and future health effects of air pollution in each of the WHO regions.

The Steering Group made recommendations to WHO on experts in epidemiology, toxicology, air quality exposure assessment, air quality management, and public policy to draft the guideline document. After initial review and approval by the Steering Group, drafts of the background chapters were distributed for external review to a wide group of experts in all the relevant disciplines. WHO also sought the opinions of air quality managers and policy makers concerning the rationale and format of the guidelines, seeking to improve their applicability in various areas of the world. An effort was made to ensure representation of a wide group of member states from all WHO regions.

WHO convened the Working Group on Air Quality Guidelines in Bonn, 18-20 October 2005, to finalize the updated WHO AQG. The Working Group consisted of authors of the draft chapters, external reviewers of the drafts, and members of the steering group (WHO 2006a, Annex 2). The tasks of the Working Group were to formulate the guidelines for the four pollutants (particulate matter, ozone, nitrogen dioxide, and sulfur dioxide) and to agree on supporting text. The report with conclusions of the Working Group meeting - after its acceptance by the Working Group members within 2 months after the meeting and WHO clearance-was published in October 2006. It is available in all WHO official languages as an executive summary of the Global Update of WHO Guidelines (WHO 2006b). The finalization of the background material, based on the comments from the Working Group members and feedback from the Steering Group, continued until June 2006.

The Steering Group also recommended supplementing the risk assessments for the four selected pollutants with an introduction. It provides an overview of the issues which must be considered in the management of air quality and, in particular, those which are critical when used for policy formulation.

\section{Challenges in formulation of the AQG}

The updated AQG are based on the now extensive body of scientific evidence relating to air pollution and its health consequences. An increasing range of adverse health effects has been linked to air pollution and at ever-lower air pollutant concentrations. This is especially true of airborne particulate matter. New studies use more refined methods 
and more subtle but sensitive indicators of effects, such as physiological measures (e.g., changes in lung function, inflammation markers). Therefore the updated guidelines are based on these sensitive indicators as well as the most critical population health indicators such as mortality and unscheduled hospitalizations.

Although this information base has gaps and uncertainties, it offers a strong foundation for the recommended guidelines. However, the use of this knowledge for creation of guidelines useful for air quality management is not straightforward.

The experts revising the guidelines agreed that no "threshold" concentration of particulate matter (PM) or ozone had been identified below which there are no adverse health effects. Therefore, no guideline value can be specified that, if achieved, will fully protect human health. However, the previous PM guideline, which comprised a mortality concentration-response function instead of a specific guideline value, was not viewed by the Working Group to be useful guide to policymakers, especially in countries where scientific infrastructure is limited. Moreover, the practical considerations of clarity and applicability of the guidelines for risk communication and management in member states with widely differing levels of local expertise and resources to devote to air quality management led the WHO working group to propose specific guideline values for each pollutant and to identify the residual health risk associated with achieving them.

In setting the PM guideline value, the Working Group considered the range of long-term average $\mathrm{PM}_{2.5}$ concentrations associated with adverse effects on chronic cardiovascular and respiratory disease in epidemiologic studies and set the guideline level $-10 \mu \mathrm{g} / \mathrm{m}^{3}$ as an annual averageat the bottom of this range. The group also took into consideration the results of time-series studies that estimate the effects of short-term exposure to $\mathrm{PM}_{2.5}$ on acute adverse health outcomes conducted in the cities with annual $\mathrm{PM}_{2.5}$ concentrations just above the selected guideline level. Table 1

Table 1 Updated WHO Air Quality Guideline values

\begin{tabular}{llr}
\hline Pollutant & Averaging time & $\begin{array}{c}\text { AQG value } \\
\left(\mu \mathrm{g} / \mathrm{m}^{3}\right)\end{array}$ \\
\hline Particulate matter & & \\
$\mathrm{PM}_{2.5}$ & 1 year & 10 \\
& $24 \mathrm{~h}$ (99th percentile) & 25 \\
$\mathrm{PM}_{10}$ & 1 year & 20 \\
& $24 \mathrm{~h}$ (99th percentile) & 50 \\
Ozone, $\mathrm{O}_{3}$ & $8 \mathrm{~h}$, daily maximum & 100 \\
Nitrogen dioxide, $\mathrm{NO}_{2}$ & 1 year & 40 \\
& $1 \mathrm{~h}$ & 200 \\
Sulfur dioxide, $\mathrm{SO}_{2}$ & $24 \mathrm{~h}$ & 20 \\
& $10 \mathrm{~min}$ & 500 \\
\hline
\end{tabular}

presents the full set of guideline values from the updated AQG.

For ozone, the selected guideline value is still in the range which has been found to increase risk of mortality by some $1-2 \%$. This residual risk was accepted by the group since ozone concentrations at the set guideline level may be due occasionally to natural phenomena, such as intrusion of stratospheric ozone into the troposphere

The Working Group was keenly aware that achieving the AQG might appear impossible in situations where air pollution levels greatly exceed the recommended guideline levels (Fig. 1). Rapid and radical improvement of air quality is rarely possible, and the recommendations have the potential to be easily ignored as not realistic. Therefore, the Working Group recommended a gradual approach to the health risk reduction and improvement of air quality, proposing a set of interim target values in moving towards the strictest guidelines. These targets aim to promote a shift from high air pollutant concentrations, which have acute and serious health consequences, to lower air pollutant concentrations. If these targets are achieved, significant reductions in risks for acute and chronic health effects from air pollution should follow (Table 2). The estimated reduction in health risks associated with the achievement of consecutive interim target levels has been specified in the AQG, allowing the authorities and the public to appreciate the result of air quality improvement results while also providing incentive for further efforts to control air pollution and reduce the risk to health. Progress towards the guideline values should, however, be the ultimate objective of air quality management and health risk reduction in all areas.

The AQG have always addressed exposures and health effects of individual pollutants or indicators (such as $\mathrm{PM}_{10}$ mass, an indicator of a complex pollution mixture with multiple sources). However, as understanding of the complexity of the air pollution mixture has improved, the limitations of controlling air pollution and its risk through guidelines for single pollutants have become increasingly apparent. Nitrogen dioxide $\left(\mathrm{NO}_{2}\right)$, for example, is a product of combustion processes and is generally found in the atmosphere in close association with other primary pollutants, including ultrafine particles. It is itself toxic and is also a precursor of ozone, with which it coexists along with a number of other photochemically generated oxidants. Concentrations of $\mathrm{NO}_{2}$ are often strongly correlated with those of other toxic pollutants. Its concentration is readily measured but needs interpretation as a potential surrogate for a set of sources and the resulting mixture. Achieving guideline concentrations for individual pollutants, such as $\mathrm{NO}_{2}$, may therefore bring public health benefits that exceed those anticipated on the basis of estimates of a single pollutant's toxicity. Therefore, while the AQG present risk 


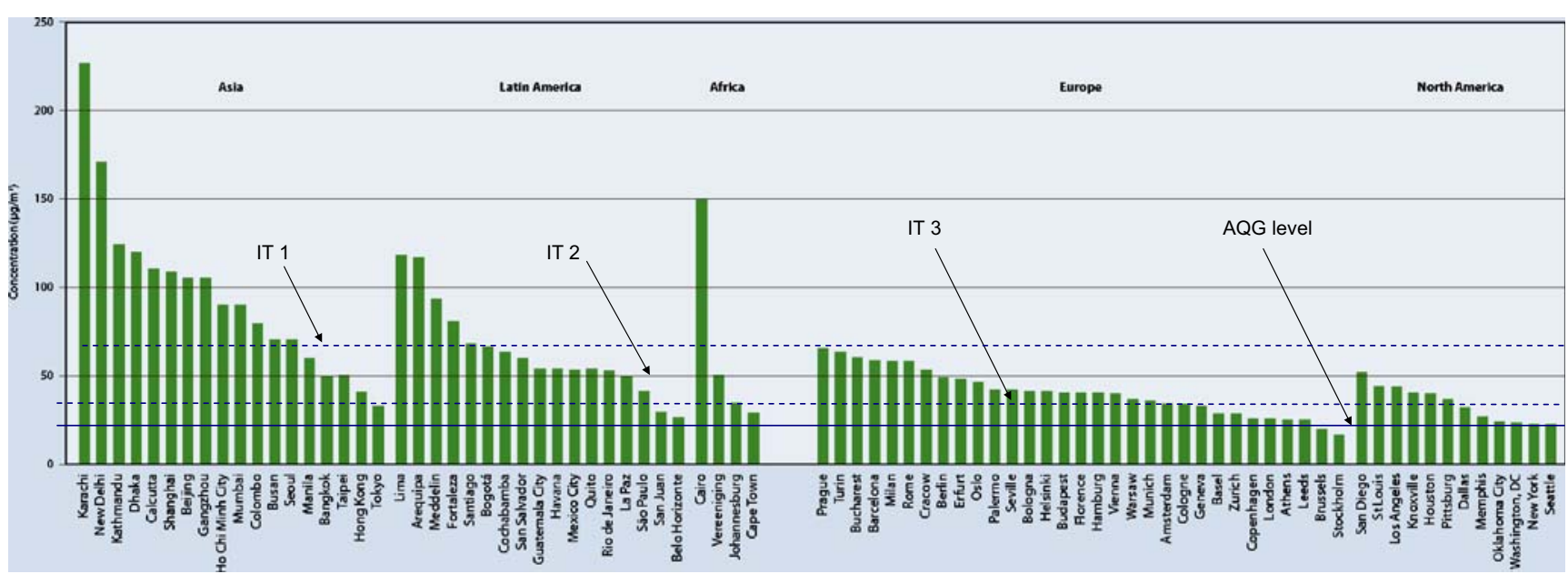

Fig. 1 Annual average $\mathrm{PM}_{10}$ concentrations $\left(\mu \mathrm{g} / \mathrm{m}^{3}\right)$ in selected large cities of the world (WHO 2006a)

assessments focused on individual pollutants, they also recommend addressing all relevant pollutants in health risk management simultaneously and particularly the four most common, for which guidelines have been reviewed.

Exposure to particulate air pollution from the combustion of solid fuels indoors was estimated to account for 1.6 million deaths in 2000, mainly among women and children in the poorest countries (Smith 2004). The AQG update considered these exposures and the burden of disease that they confer and noted that "Given the recent evidence... it is now reasonable to propose using the same air quality guidelines for both indoor and outdoor exposures." Although the current guideline values were considered by the WHO Working Group to apply to all non-occupational micro-environments, the update noted "...there is currently a lack of data on indoor air pollution and exposure in vulnerable populations, and such data are not likely to become available [in the near future]...This means that the applicability of [the results of] outdoor air pollution studies to solid fuel use....in developing countries is not ...the most critical issue. Rather, the priority is [to develop] guidelines that can be realistically assessed in communities most at risk...and translated into [relevant] standards..." (WHO 2006b, Chapter 9, page 202). Guidelines specifically tailored to indoor combustion of solid fuels are currently being developed by WHO.

The present revision of the AQG provides new guideline values for three of the four pollutants examined. For two of them (particulate matter and ozone), it is possible to derive a quantitative relationship between the concentration of the pollutant, as monitored in ambient air, and specific health outcomes, such as mortality. These relationships are invaluable for health impact assessment and allow insights into the mortality and morbidity burdens from current levels of air pollution as well as the health improvements expected under different air pollution reduction scenarios. The burden-of-disease estimates can also be used to estimate the costs and benefits of interventions that reduce air pollution (AEAT 2006). Approaches to, and the limitations of, health impact assessments are summarized in one of the chapters of the newly published AQG. In particular, selection of the concentration-response functions, reference levels, and assumptions regarding populations for which the impact evaluations are done require special considerations. WHO recently estimated the burden of disease due to exposure to particulate matter above the

Table 2 WHO air quality guidelines and interim targets for particulate matter: annual mean concentrations

\begin{tabular}{|c|c|c|c|}
\hline & $\mathrm{PM}_{10}\left(\mu \mathrm{g} / \mathrm{m}^{3}\right)$ & $\mathrm{PM}_{2.5}\left(\mu \mathrm{g} / \mathrm{m}^{3}\right)$ & Basis for the selected level \\
\hline Interim target-1 (IT-1) & 70 & 35 & $\begin{array}{l}\text { These levels are associated with about a } 15 \% \text { higher long-term mortality } \\
\text { risk relative to the AQG level }\end{array}$ \\
\hline Interim target-2 (IT-2) & 50 & 25 & $\begin{array}{l}\text { In addition to other health benefits, these levels lower the risk of premature } \\
\text { mortality by approximately } 6 \%(2-11 \%) \text { relative to the IT- } 1 \text { level }\end{array}$ \\
\hline Interim target-3 (IT-3) & 30 & 15 & $\begin{array}{l}\text { In addition to other health benefits, these levels reduce the mortality risk } \\
\text { by approximately } 6 \%(2-11 \%) \text { relative to the IT- } 2 \text { level }\end{array}$ \\
\hline Air Quality Guideline & 20 & 10 & $\begin{array}{l}\text { These are the lowest levels at which total, cardiopulmonary, and lung } \\
\text { cancer mortality have been shown to increase with more than } 95 \% \text { confidence } \\
\text { in response to long-term exposure to } \mathrm{PM}_{2.5}\end{array}$ \\
\hline
\end{tabular}


AQG levels using concentration-response functions as described by Cohen et al. (2004). These estimates indicate that approximately 800,000 premature deaths and more than 6 million years of life lost annually can be attributed to air pollution exposure in large cities of all WHO member states (WHO 2007), with most of the impact occurring in Asia (Fig. 2).

\section{Use of the guidelines in policy formulation}

The introductory chapters of the updated AQG document the wide diversity of air quality in the world, posing quite different challenges to air quality management. In many areas with high levels of pollution, pollution reduction is technically feasible, but political or socio-economic considerations are critical determinants, and lack of organizational capacities of the administration may limit the effectiveness of air quality management.

In many developed countries, air quality has improved in recent decades. Further progress, necessary for the reduction of adverse impacts of pollution on health observed even at those low pollution levels, requires development and use of new technologies and often potential changes in lifestyle and in the urban landscape. While the costs of this development are estimated to often be orders of magnitude below the benefits due to prevented morbidity and mortality (AEAT 2006), the clear rationale for such actions, given by the AQG, is an important factor to catalyze such actions.
At present, a plan is not in place for a comprehensive, systematic evaluation of the use of the AQG in policy formulation or their impact on national standard-setting practices, though such an evaluation would be useful to WHO to assess the utility of the current AQG and in designing future guidelines. An ongoing project undertaken at the University of California, Berkeley, may bring the first assessment of this issue (Smith $\mathrm{K}$ and Vahlsing $\mathrm{C}$, private communication). Although the time since publication of the "Global update 2005" (WHO 2006b) is too short to assess their full impact, there are already several instances showing that the results of the WHO evaluation of the health risks of air pollution - either the AQG themselves or the risk assessment conducted earlier-have been used by national and international entities. Examples of such applications by political bodies include the reference to the WHO work in the Thematic Strategy on Air Pollution or in air quality directive of the European Commission (CEC 2006, EC 2005) or by the French High Commission on Public Health (HCSP 2007). The updated AQG has also been used as an argument in discussion on new European air quality regulations by scientific and health-related groups (Annesi-Maesano et al. 2007).

Civil initiatives, as a "Campaign for clean air in London," call for achievement of air quality according to the WHO AQGs (AQ 2007).

Several reports, prepared either by WHO or other international organizations, use the guideline levels as benchmarks for their assessment. For instance, as noted above, the burden of disease related to air pollution in large
Fig. 2 Estimated impacts of exposure to particulate matter exceeding WHO AQG level in large cities in various regions of the world (see WHO 2007 for definition of the regions)

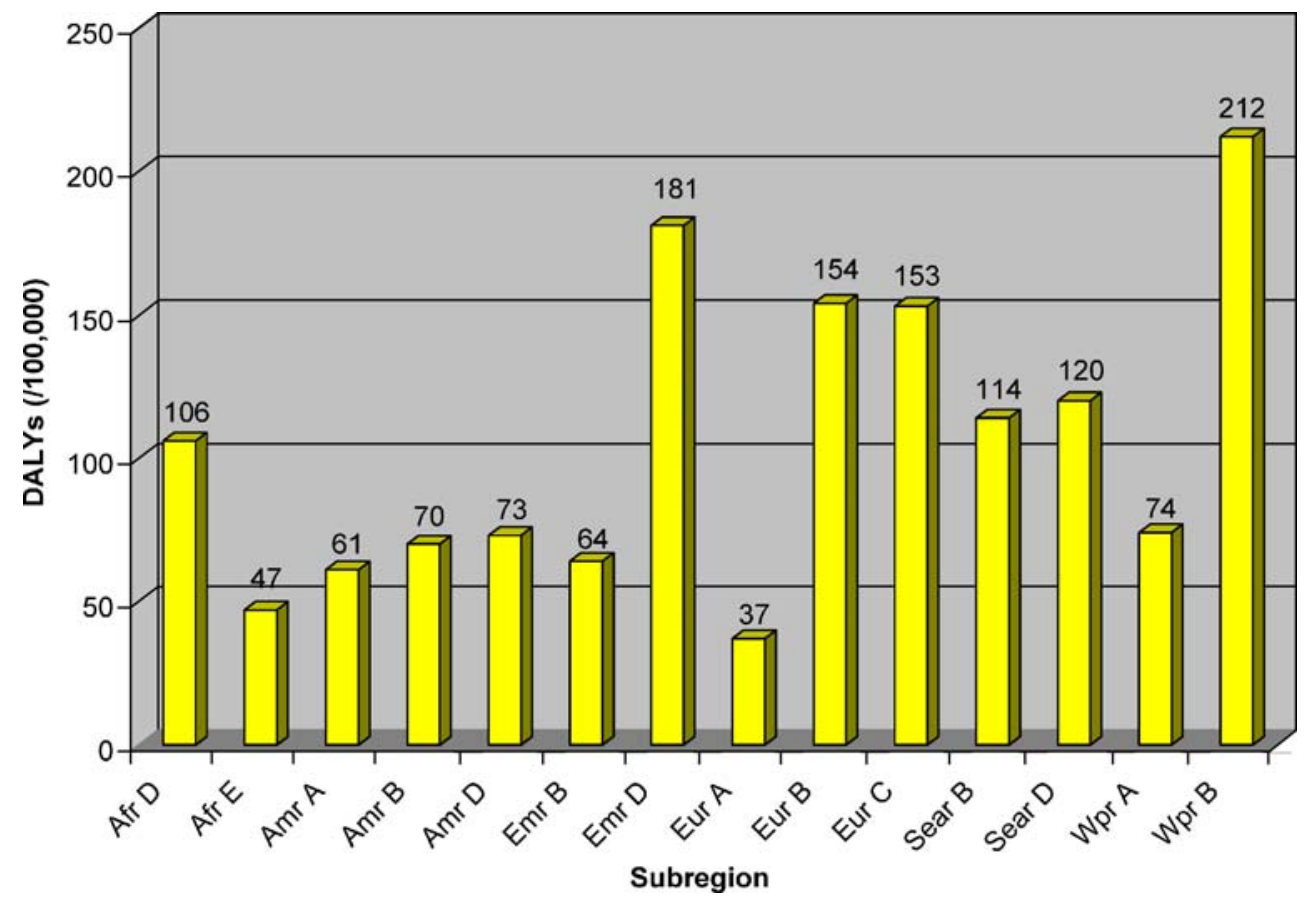


cities of each of the WHO member states has been estimated for PM levels in excess of the AQG levels for $\mathrm{PM}_{10}$ (WHO 2007). The Organization for Economic Cooperation and Development (OECD) Environmental Outlook uses the WHO AQG as the reference (OECD 2007). A recently published national analysis of air quality in Spain refers to AQG levels and interim targets as benchmarks and indication of the severity of air pollution problems in Spanish cities (Moreno et al. 2007).

Since their adoption, the WHO AQGs have also begun to receive attention in Asia and Latin America, where they provide a focal point for the discussion of air quality and health. In 2006, following the presentation at a major Asian air quality meeting of the AQGs and estimates of the health impacts associated with their exceedance in Asian cities, government officials and international lending agencies called for concerted action to reduce air pollution (http:// www.iht.com/articles/ap/2006/12/13/asia/AS_GEN_ Asia_Air_Pollution.php; The Jakarta Post, Vol.24, No.228, Page 1, Thursday, December 14, 2006). More recently, a press conference at a major environmental health meeting in Mexico City resulted in extensive media coverage of the AQG and health impacts of air pollution in Mexico City and Latin America, with articles appearing in 14 newspapers (e.g., Diario Monitor, September 7, 2007, Page 2A; HEI Update Newsletter, Winter 2007-2008).

\section{Discussion}

The updated AQGs are based on the best available scientific evidence and are developed with involvement of leading experts and with consideration and responsiveness to the diverse situations around the globe. Therefore, they can play an important role in reduction of the disease burden from air pollution. Based on the thorough risk assessment, the AQG propose reduction of population exposure to the most common air pollutants, giving clear objectives and milestones.

Formulation of the guidelines reflects an impressive body of relatively recent research on the health effects of air pollution. However, gaps remain in the scientific evidence, and additional research could enhance the effectiveness of air quality management in reduction of health risks. Specific questions relate to the significance of selected sources of pollution in causing the health effects, timing and time pattern of exposure, or the role of personal vulnerability (such as health status, nutrition, and genetic predisposition). Differences of pollution mix, of exposure pattern, population susceptibility, and vulnerability in various parts of the world, potentially involved in producing the health effects, call for expanding the studies beyond the regions where most of the studies were conducted to date, i.e., to the developing countries. Currently, most developing countries lack the resources, including technical capacity, to conduct research on the health effects of air pollution. International efforts could facilitate conducting research and building local capacity in developing countries. Such research will provide much-needed local evidence, adding to scientific knowledge and empowering local decision-makers. We need not, however, wait for the results of future research to address the public health challenges posed by air pollution, especially in the developing countries of Asia, Africa, and Latin America where the air pollution levels greatly exceed those in developed countries and where, as a result, the burden of disease due to air pollution is the greatest. The AQG provide clear health-based recommendations on the targets for air pollution reduction and provide an impetus for the efforts of these countries in finding the most effective methods for pollution reduction. International community assistance in these efforts will benefit the local population and reduce pollution transported over long distances that affects populations on a global scale.

Disclaimer The views expressed in this paper are those of the authors and do not necessarily reflect the views of the Health Effects Institute (HEI) or its sponsors.

\section{References}

AEAT (2006) An update on cost-benefit analysis for the CAFÉ Programme. AEAT/ ED48763001/CAFE-CBA update, November 2006. Issue $2 \mathrm{http} / / / \mathrm{ec}$.europa.eu/environment/air/cafe/pdf/ cba update nov2006.pdf

AQ 2007. Air quality: Campaign for clear air in London. http://www. bbc.co.uk/dna/actionnetwork/G1956

Annesi-Maesano I, Forastiere F, Künzli N et al (2007) Particulate matter, science and EU policy. Eur Respir J 29(3):428-31 (Mar)

Cohen A et al (2004) Mortality impacts of urban air pollution. In: Ezzati $\mathrm{M}$ et al (ed) Comparative quantifcation of health risks: global and regional burden of disease attributable to selected major risk factors. Geneva, World Health Organization, pp 1353-1434

CEC (2006) Council of the European Union (2006) Thematic strategy on air pollution-Council conclusions. Brussels 15 March 2006 (7329/06). http://ec.europa.eu/environment/air/cafe/pdf/council_ concl them strategy.pdf

EC (2005). Commission of the European Communities (2005) Proposal for a Directive of teh European Parliament and of the Council on ambient air quality and cleaner air for Europe. COM (2005) $447 \mathrm{http} / / /$ ec.europa.eu/environment/air/cafe/pdf/cafe dir en.pdf

HCSP (2007) Avis relative au project de Directive européenne sur la qualité de l'air ambiant. 7 novembre 2007. Haut Conseil de la santé publique. http://www.hcsp.fr/hcspi/docspdf/avisrapports/ hcsp044a20071107_DEQualiAir.pdf

HEI (2004) Health effects of outdoor air pollution in developing countries of Asia: a literature review. Boston, MA, Health Effects Institute, 2004 (Special Report 15).

Moreno T, Querol X, Alastuey A et al (2007) Airborne particulate matter and premature deaths in urban Europe: the new WHO 
guidelines and the challenge ahead as illustrated by Spain. Eur J Epidemiol 22:1

OECD (2007) Environmental outlook to 2030. DRAFT 23.07.2007 $\mathrm{ENV} / \mathrm{EPOC} / \mathrm{RD}(2007) 11 / \mathrm{REV} 1$

PAHO (2005) An Assessment of Health Effects of Ambient Air Pollution in Latin America and the Caribbean. Pan American Health Organization, Washington, DC. PAHO, 2005.

Smith KR et al (2004) Indoor air pollution from household use of solid fuels. In: Ezzati $\mathrm{M}$ et al (ed) Comparative quantification of health risks: global and regional burden of disease attributable to selected major risk factors. Geneva, World Health Organization, pp 1435-1494

WHO (2000a) Evaluation and use of epidemiological evidence for environmental health risk assessment. World Health Organization, Regional Office for Europe, Copengahen 2000 (E68940) http://www.euro.who.int/document/e68940.pdf (also: Environ Health Perspect 108:997-1002 (2000))

WHO (2000b) Air quality guidelines for Europe; second edition Copenhagen, WHO Regional Office for Europe, 2000 (WHO regional publications. European series; No 91), (full background material available on http://www.euro.who.int/air/activities/20050223 4)

WHO (2004a) Health aspects of air pollution. Results from WHO project "Systematic review of health aspects of air pollution in Europe". WHO Regional Office for Europe, 2004 http://www.euro.who.int/ document/E83080.pdf

WHO (2004b) Comparative quantification of health risks: global and regional burden of disease attributable to selected major risk factors. World Health Organization 2004

WHO (2006a) Air Quality Guidelines. Global update 2005. World Health Organization 2006. http://www.euro.who.int/Document/ E90038.pdf

WHO (2006b) Air Quality Guidelines for particulate matter, ozone, nitrogen dioxide and sulfur dioxide. Global update 2005. Summary of risk assessment. World Health Organization 2006 http://www. who.int/phe/health_topics/outdoorair_aqg/en/index.html

WHO (2007) Global estimates of burden of disease caused by the environmental and occupational risks http://www.who.int/quanti fying_ehimpacts/global/urbair/en/index.html 